\title{
Importance of Ethics in Drug Advertising
}

\author{
Chitra Khanwelkar ${ }^{1}$, Vivek Phirke ${ }^{2}$, Poovishnu Devi T. ${ }^{3}$, Sujata Jadhav ${ }^{1}$, \\ Vandana Thorat ${ }^{1}$. \\ ${ }^{1}$ Department of Pharmacology, Krishna Institute of Medical Sciences, KIMSDU, Karad \\ ${ }^{2}$ Cognizant Technology Solutions \\ ${ }^{3}$ Krishna College of Physiotherapy, KIMSDU, Karad. \\ Corresponding Author: Chitra Khanwelkar \\ E-mail: hodpharmacology@kimsuniversity.in
}

\begin{abstract}
The drug promotional literatures are used as one of the source of drug information by a busy practitioner due to time constraint. The information in these literatures should be unbiased, factual, evidence based and non-misleading; otherwise the prescriber's choice of drug may get influenced. The doctors should develop an art of critically evaluating the promotional literatures. Direct to consumer advertising of drugs should be stringently controlled by the regulatory authorities so as to increase safe use of drugs.
\end{abstract}

Keywords: Drug promotional literature, WHO guidelines, Ethics, DTCA.

\section{INTRODUCTION}

Unbiased sources of drug information play a vital role in any physician's clinical practice. After graduation from medical school, the practicing doctor can get information from text books, scientific journals, conferences, continued medical education programs, Drug Indices, Pharmacopoeias, Drug Compendia, Internet. Though all these sources are authentic, they have their inbuilt shortcomings. Text books are revised only once in few years and may not contain information of new approved drugs. Pharmacopoeia contains lot of other information like purity, ingredients etc. Internet is having lot of information and due to pro and anti information about a single molecule; the prescriber might get confused or might get unnecessarily influenced. Considering the busy schedules of practicing doctors in country like India, the prescriber use the information given by pharmaceutical companies through medical representative's visits, drug promotional literature in form of leaflets, booklets, videos, models etc; for deciding choice of drug to be prescribed. The prescribers are tempted to believe the information blindly and this is boosted by gifts and perks offered to them by companies. Though information obtained from these literatures cannot be said to be completely unscientific and false, to some extent it can be misleading, biased and may be hiding few facts, because ultimately, they are prepared to enhance sell of that medicine.

The World Health Organization has set guidelines for ethical promotion of drugs [1]. In India standards are set by Organization of Pharmaceutical Producers of India (OPPI) [2] adhering to guidelines given by The International Federation of Pharmaceutical Manufacturers and 
Association (IFPMA). But unfortunately, all these guidelines are not followed or implemented effectively in India and many other developing countries.

\section{ETHICAL ISSUES IN DRUG ADVERTISEMENTS}

There are many objections raised about ethical behavior and factual information provided pertaining to the drug advertisements and promotional drug literatures -

1. The promotional drug literatures are printed on very glossy papers and have very attractive photographs, pictures. Actually, this should not be an ethical issue, as the very purpose of these advertisements is commercial and to attract the prescriber. But printing unrelated pictures like beautiful smiling face of a girl or a film artist on a vitamin supplement preparation/ hematinic product advertisement, printing famous athlete's photo on calcium supplement, a giraffe picture on baby food can be called misleading. Few advertisements give wrong ideas about efficacy of drug. e.g. In the advertisement of an analgesic, an old patient of knee joint arthritis is shown running in marathon after taking drug. All these attracting techniques should not influence prescriber's choice of drug, as the prescriber needs to be learned and expected to think scientifically. Such advertising gimmicks will definitely influence the lay person and therefore they are objectionable in direct to consumer advertising (DTCA) of drugs.

2. Printing exaggerated claims about effect and potency of that product: It is objectionable and misleading if there are claims like 'The best among all', 'First line', 'Safest', 'First choice of physicians' etc. Sometimes the claims are not only exaggerated but are false also. In a study about evaluation of drug promotional literature (DPL) provided by medical representatives at a tertiary care hospital in India; 61.3\% DPLs had at least one claim. The authors reported many false claims, like multivitamin preparation has memory enhancer, Montelukast and fexofenadine as cardio safe, ofloxacin and cefixime as gold standard for acute uncomplicated urinary tract infection [3].

3. No educational value: The advertisement should contain information about indications, adverse effects, drug interactions, contraindications, dosage regimens of that medicinal substance as guided by WHO [1], but many advertisements give incomplete information. The indications and advantages are printed in bold and larger font and are eye catching. The adverse effects and interactions are most of the times very incompletely mentioned and in a very small font which is impossible to read for prescriber. This practice is very harmful for patients if doctors depend on DPLs as source of drug information. Few studies about validation of DPLs based on IFPMA guidelines and WHO guidelines report the deviation from these guidelines. Clinical indications were correctly mentioned in $51.85 \%$ DPLs in one study [4] and $94.7 \%$ in another [5]. The adverse reactions were completely mentioned only in $23.7 \%$ [3] and $14.7 \%$ [5] DPLs. Interactions mentioned in only $17.5 \%$ [3] and 6.7\% [5] DPLs. Dosage regimens were given in 38.1\% [3], 59.25\% [4] and 42\% [5] DPLs. It was surprising that in one study $42 \%$ DPLs were not having mention of pharmacological actions of drug [5].

4. Playing with emotions: Some advertisements particularly of nonprescription, OTC drugs give some emotional touch to the pictures or information. These drugs can be purchased by lay public from chemist shops. The consumer's choice of brand can get influenced by such advertisements. A prospective mother can purchase calcium, iron and vitamin preparations by getting influenced by picture showing breast feeding mother and a chubby baby. She can purchase a product which shows very emaciated baby and a tag line "You definitely don't want your baby to look like this". Here fear is created in her mind that if she does not take this drug her baby will become unhealthy. Another example is the advertisement of a lipid lowering drug showing a man getting severe chest pain suggestive of heart attack.

5. Hiding of important information: A rare but life-threatening adverse effect or interaction might not be printed in the literature. In a study done by Kothari Parli and others, 194 DPLs were evaluated. Significantly high \% of DPLs had incomplete information about 
adverse effects, safety precautions, contraindications and drug interactions [3]. This is highly unethical as this can lead to irrational prescribing.

6. Lame scientific proofs and references: Many a times to support the claims about efficacy, safety of the new molecule in comparison with existing old molecule, references of clinical trials are given. But if we see in detail, these are publications by same manufacturing pharmaceutical company. Sometimes out of context sentences picked from authentic textbooks are also printed on advertisements. This definitely creates false assurance about safety and efficacy of that product in the prescriber's mind. Many a times the quoted comparative studies are not valid studies. But mere mention of some study apparently increases credibility of study. In a study out of total 299 claims about superiority of drugs in DPLs only 75 claims were supported by references. Out of these 75 references 10 were not retrievable, 4 were from journal articles, 4 were from data file and 2 were from websites [6].

7. Modified Graphs and charts: In this era of evidence-based medicine, doctors get impressed if graphs are given in drug information, its authenticity increases. The unethical issue in this aspect is giving graphs having numerical distortion, improper $\mathrm{X}$ or $\mathrm{Y}$ axis, chart junks like presence of extra grid lines, color schemes to make readings of advertised drug more prominent. Thus, deceptive presentation of results may have prominent influence on prescriber's mind.

8. Legibility of generic name: Usually the brand name is highlighted by using dazzling colors and very big font size. The generic name of drug is many times in very small font. This definitely encourages brand prescribing. Now fortunately writing generic name in prescriptions is made mandatory by the regulatory authorities.

9. Direct to consumer advertising (DTCA): In India marketing of drugs is directed to doctors and DTCA is not allowed. Because of this advertising in public press, magazines, radio public gets information about diseases and they start approaching their doctors for that treatment. This increases the sale of the drug. Drug companies can powerfully touch important feelings of public like fear of death, value of own and loved one's life, fear of disability, vulnerability of age, gender. Though DTCA are not allowed in many countries, they definitely create public awareness about disease and availability of treatment and motivates patient to become active decision maker about own health. But in country like India and many other developing countries having uneducated population; either DTCA is dangerous or it may be wasteful also.

In India for nonprescription allopathic drugs and drugs of alternative medicinal systems (Unani, Ayurveda, Homeopathy) DTCA is not prevented. Advertisements of these drugs are released in newspapers, magazines, radio, television and internet. Most of these advertisements are violating the guidelines of WHO, IFPMA and OPPI. They are unscientifically presented like advertisements of the cosmetic products. Many film stars are involved as models in these. Mostly drugs recommended for obesity, hematinics, antitussives, drugs in erectile dysfunction, nutraceuticals, pain balms and purgatives are advertised like this. These advertisements are not mentioning generic names of drug, adverse effects, contraindications, interactions. False tall claims are freely made in these advertisements. People purchase and consume these drugs without consulting doctors. Ayurvedic preparations are found to contain non permissible levels of heavy metals. Few cases of chronic lead poisoning are reported where patients were taking some such products as medicine for diabetes. Another risk associated with use of such drugs is, patients get false assurance about taking treatment for the diabetes, hypertension etc. and they stop their allopathic prescribed medicine without consulting doctor. Due to this they might be losing control on blood sugar and blood pressure. Many interactions of these drugs with allopathic drugs are also documented. Thus, advertising of these drugs done without considering WHO guidelines may result into fatal consequences or morbidities in patients, unknowingly.

In a comparative study of drug advertisements in scientific journals it is reported that the fulfillment of the IFPMA criteria was significantly higher in non-Indian journals (mainly journals from the 
United States and United Kingdom) than in Indian journals [7]. This clearly suggests that stringent control of regulatory authorities on DPLs in developing countries in required.

\title{
RESPONSIBILITY OF PRESCRIBERS
}

In this scenario the onus of rational prescribing lies on prescribers. They should take precaution while deciding about drugs to be prescribed. They can use information obtained from advertisements for getting knowledge about drugs, but should verify its authenticity. They should depend more on peer discussion, text books and authentic scientific journals. They should be able to read promotional literature critically and should develop scientific approach. They should realize the importance of time-tested new drugs and should remember that every new drug may not be better than the established one. As per Indian Medical Council (Professional Conduct, Etiquette and Ethics) Amendment Regulation 2009 part I, a medical practitioner shall not receive any gift, travel facility, hospitality from drug manufacturing company. Ethically this practice of drug companies is to be condemned by doctors as they feel compelled to prescribe a certain drug due to these obligations. The prescriber should be courageous about raising questions about false claims, wrong information in drug promotional literatures. Currently the students of medical schools are not given education about guidelines of drug advertising. Very few medical schools have a practical exercise dealing with critical appraisal of promotional drug literature.

Patients should take medicines only after consulting the doctors. They should not get tempted by the attractive claims in advertisements. Creating awareness about risks in self medication practices among society is very important step to be taken. The health professionals can contribute to this noble work. If pharmaceutical companies, prescribing doctors and patients play their roles ethically and responsibly, the rational use of drug will be enhanced and safety in use of drugs will be increased. This will consequently reduce economic burden on health care system of nation.

\section{REFERENCES}

1. Ethical Criteria for Medicinal Drug Promotion. Geneva: World Health Organization; 1988. Available from: http://www.who.int/medicinedocs/documents/whozip08e/whozip08e.pdf.

2. OPPI Code of Pharmaceutical Marketing Practices. Organization of Pharmaceutical Producers of India (OPPI); 2012. Available from http://www.indiaoppi.com/OPPI\%20Code\%20of\%20Pharmaceutical\%20Practices\%20\%20- \%2 02012.pdf.

3. Parli K, Reema R, Devang R, Supriya M. Evaluation of promotional drug literature provided by medical representative at a tertiary care hospital. Int J Pharm Sci Res 2017;8(4):1744-50.

4. Shagupta A Naikwadi. Critical Analysis of Indian Drug Promotional Literature (DPL) Using World Health organization Criteria For Ethical Medicinal Drug Promotion. IOSR J Dental Med Sci 2017:1:49-54.

5. Hoovinahole S, Kamath A. A study of adherence of drug promotional literatures from various clinical specialties to the World Health Organization ethical criteria for drug promotion. J Pharm Negative Results 2016;7:37-41.

6. Jadhav SS, Dumatar CB, Dikshit RK. Drug promotional literatures (DPLs) evaluation as per World Health Organization (WHO) criteria. J Appl Pharmaceut Sci 2014;4(6):84-8.

7. Vachhani PM, Solanki MN, Desai MK. An evaluation of drug promotional literatures published in scientific medical journals. J Pharm Biol Sci 2016;8:248-52.

\author{
Acknowledgements: Nil \\ Funding: Nil \\ Conflict of interest: None
}

